\title{
Characterization of Human Renal Stones with MDCT: Advantage of Dual Energy and Limitations Due to Respiratory Motion
}

\section{Romain Grosjean \\ Benoît Sauer ${ }^{1,2}$ \\ Rui Matias Guerra1,3 \\ Michel Daudon ${ }^{4}$ \\ Alain Blum² \\ Jacques Felblinger ${ }^{1}$ \\ Jacques Hubert ${ }^{1,5}$}

Keywords: chemical composition, CT attenuation value, nephrolithiasis, renal stones, respiration motion

\section{DOI:10.2214/AJR.07.2466}

Received August 25, 2007; accepted after revision October 3, 2007.

${ }^{1}$ Interventional and Diagnostic Adaptative Imaging, INSERM ERI 13, Nancy University, Centre Hospitalier Universitaire Nancy (TD4), Rue du Morvan, 54511 Vandœuvre-les-Nancy CEDEX, France. Address correspondence to R. Grosjean (r.grosjean@chu-nancy.fr).

${ }^{2}$ Department of Radiology, Service d'Imagerie Guilloz, Centre Hospitalier Universitaire, Nancy, France.

${ }^{3}$ Siemens Medical Solutions, Saint Denis, France.

${ }^{4}$ Cristal Laboratory, Necker Hospital, Paris, France.

${ }^{5}$ Department of Urology, Centre Hospitalier Universitaire, Nancy, France.

AJR2008; 190:720-728

0361-803X/08/1903-720

(ㄷ) American Roentgen Ray Society

OBJECTIVE. Our aim was to determine, using CT attenuation values, the chemical composition of 241 human renal stones placed in a jelly phantom and to analyze the influence of respiratory motion on the classification.

MATERIALS AND METHODS. The stones were placed in a jelly simulating the X-ray attenuation of the kidneys. A dynamic platform was used to apply to the phantom free-breathing motion (sinusoidal motion in $z$-axis) and motion due to lack of maintenance of a breath-hold $\left(5 \mathrm{~mm} \cdot \mathrm{s}^{-1}\right.$ in $z$-axis). Determination of the chemical composition was performed with mean CT attenuation values obtained at 80 and $120 \mathrm{kV}$ and with dual-energy CT attenuation values.

RESULTS. Two hundred forty-one human urinary stones were classified into six groups: uric acid, cystine, struvite, weddellite (calcium oxalate dihydrate), whewellite (calcium oxalate monohydrate), and brushite. With no motion, the use of dual energy enabled differentiation of all of the types of stones with statistically significant differences. Uric acid $(-20 \pm 22 \mathrm{H})$, cystine $(106 \pm 19 \mathrm{H})$, struvite $(271 \pm 16 \mathrm{H})$, weddellite $(323 \pm 5 \mathrm{H})$, brushite $(415 \pm 30 \mathrm{H})$, and whewellite $(510 \pm 17 \mathrm{H})$ were identified as distinct groups. Motion-induced mean CT attenuation values were significantly different from those obtained with no motion. With motion, dual-energy CT attenuation values did not allow differentiation of all stone types.

CONCLUSION. Dual-energy CT attenuation values can be used to predict the chemical composition of stones in vitro. However, when slight motion is applied to renal stones during image acquisition, the values become significantly different from those obtained with no motion. Consequently, confusion arises in differentiating stone types. A perfect breath-hold has to be performed for in vivo use of attenuation value to discern stone type.

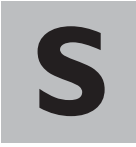
ince the early 1990s, the use of unenhanced CT has gained widespread acceptance in the evaluation of nephrolithiasis. Because studies have shown that helical CT can depict urinary stones more precisely than do radiography [1], sonography [2], nephrotomography [3], and excretory urography [4], MDCT has become the technique most used for rapid and accurate determination of the presence of stones in evaluations for urinary lithiasis treatment [5-10].

Precise determination of the symptoms, localization, size, and chemical composition of stones is key to diagnosis and choice of therapy [11]. Extracorporeal shock wave lithotripsy is the most commonly used technique in the management of urinary stones, but the success of this treatment depends on the chemical composition of the stone and its corresponding fragility [12-15]. For example, brushite, cystine, and calcium oxalate monohydrate stones are more resistant to extracorporeal lithotripsy [16] than are the other types of stones we describe. Failure of extracorporeal shock wave lithotripsy increases medical costs, necessitates alternative treatment, and results in undesirable exposure of the renal parenchyma to shock waves. For these reasons, pretreatment determination of the composition of stones is essential. Since the early 1980s, studies have been conducted to determine stone composition on the basis of X-ray attenuation of stones in vitro [17-22] and in vivo [23-25].

Organs in the upper part of the abdomen, including the liver, kidneys, and spleen, move considerably as a result of respiration [26]. McCollough et al. [27], Alfidi et al. [28], and Ritchie et al. [29] have proved that physiologic motion decreases the quality of CT images. To our knowledge, no studies have been conducted to evaluate the influence of residual respiratory motion on the 
CT attenuation values of stones. The aim of our study was to determine with CT attenuation values the chemical composition of human renal stones in a jelly phantom and to analyze the influence of respiratory motion on stone classification.

\section{Materials and Methods Urinary Stones}

Data on 241 urinary stones from humans were obtained from the database of a stone analysis laboratory. The stones had been collected through surgical and endoscopic intervention. The biochemical composition had been determined with stereomicroscopy and infrared spectrophotometry, which generated the percentages of the predominant components. The percentages of pure and mixed stones were not equal. On average, two thirds of calculi were polycrystalline. The stones were classified according to the main component, and only stones containing at least $85 \%$ of one component were used for our study. According to the predominant component, the stones were divided into six groups: uric acid, cystine, magnesium ammonium phosphate hexahydrate (struvite), calcium oxalate dihydrate (weddellite), calcium oxalate monohydrate (whewellite), and calcium hydrogen phosphate dihydrate (brushite) (Table 1). All of these stones had low content of a secondary component. The diameter of the stones varied from 7 to $25 \mathrm{~mm}$ (mean size, $12 \mathrm{~mm}$ ).

\section{Phantom and Dynamic Platform}

The stones were placed in a jelly made of water, iodine, and animal proteins (Fig. 1). The iodine and protein concentrations were empirically chosen to ensure the jelly had an X-ray attenuation similar to that of human kidney $(30 \mathrm{H}$ at $120 \mathrm{kV})$. To $1 \mathrm{~L}$ of water, we added $21.6 \mathrm{~g}$ of animal protein and $0.01 \mathrm{mg}$ of iodine. Each layer of jelly, containing all the stones of one type, was successively settled in a plastic container $(280 \times 210 \times 110 \mathrm{~mm})$. The jelly phantom was homogeneous $(30 \pm 3 \mathrm{H})$. Stones were embedded in a layer $3 \mathrm{~cm}$ thick. The jelly phantom had six layers, for a total thickness of $18 \mathrm{~cm}$. The plastic container was placed in a water tank. This water tank containing the six layers of jelly and the 241 stones was placed on a dynamic platform designed to accurately simulate respiratory motion in the $z$-axis [30].

\section{Applied Motion}

Two motions were used: a simulation of freebreathing motion and a simulation of motion due to lack of maintenance of a breath-hold. For free breathing, a sinusoidal motion, described by Lujan et al. [31], was applied with an amplitude of $35 \mathrm{~mm}$
TABLE I: Repartition of Calculi Used for In Vitro Study

\begin{tabular}{l|c}
\hline \multicolumn{1}{c|}{ Stone Type } & $n$ \\
\hline $\begin{array}{l}\text { Brushite (calcium hydrogen phosphate } \\
\text { dihydrate) }\end{array}$ & 12 \\
Cystine & 64 \\
$\begin{array}{l}\text { Struvite (magnesium ammonium } \\
\text { phosphate hexahydrate) }\end{array}$ & 29 \\
Uric acid & 38 \\
Whewellite (calcium oxalate & 63 \\
monohydrate) & \\
Weddellite (calcium oxalate dihydrate ) & 35 \\
\hline Total & 241 \\
\hline
\end{tabular}

and a period of 5 seconds, as proposed by Moerland et al. [32] and proved by Pasquier et al. [33]. To achieve independence from the phase of freebreathing motion, we performed three acquisitions with free-breathing motion and averaged the data obtained. For breath-hold motion due to lack of maintenance of a breath-hold, the phantom was translated in the longitudinal axis ( $z$-axis) with a speed of $5 \mathrm{~mm} / \mathrm{s}$. To simulate a perfect breath-hold, the platform was kept at rest.

\section{CT Parameters}

MDCT (Somatom Sensation 16, Siemens Medical Solutions) was performed at 80 and $120 \mathrm{kV}$, $200 \mathrm{mAs}, 0.5$-second gantry rotation time, 0.75 $\mathrm{mm}$ collimation, and $0.7-\mathrm{mm}$ index of reconstruction. These parameters were those used in a typical abdominal examination protocol.

\section{Image Analysis}

For measurement of $\mathrm{CT}$ attenuation values at image analysis, we devised an interface based on Matlab (Mathworks). Stones were segmented from multiplanar reformation by use of standard morphologic image-processing operations (global threshold of $155 \mathrm{H}$, opening to remove pixel inferior in relation to three pixels and closing to gather the contiguous zones separated by the thresholding). For each acquisition and for each stone, the largest region of interest (ROI) was set closest to the largest area of the stone (Fig. 2). The size and the position of the ROIs had been validated twice by an experienced radiologist using a conventional soft-tissue window. A conventional soft-tissue window (width, $350 \mathrm{H}$; level, $40 \mathrm{H}$ ) was used to record the mean $\pm \mathrm{CT}$ attenuation values within the ROI.

\section{Data and Statistical Analysis}

Determination of chemical composition was performed with mean $\mathrm{CT}$ attenuation value at $80 \mathrm{kV}$, mean CT attenuation value at $120 \mathrm{kV}$, and dual-energy CT attenuation value. Dual-energy $\mathrm{CT}$ attenuation value was assessed by subtracting the mean CT attenuation value obtained at $120 \mathrm{kV}$ from the mean CT attenuation value obtained at $80 \mathrm{kV}$. The $95 \%$ CI (lowest to highest) was computed. The $95 \%$ CI obtained with no motion was considered the reference for the rest of the study. To compare mean CT attenuation values for the different types of motion (perfect breath-hold vs nonmaintained breath-hold, perfect breath-hold vs free breathing, nonmaintained breath-hold vs free breathing), a paired Student's $t$ test for two sets of unpaired data with unequal variance assumed was used. The same test was performed to compare the dual-energy CT attenuation values of the different types of stones.

\section{Results}

Static Acquisitions (Perfect Breath-Hold)

At $80 \mathrm{kV}$, according to the mean CT attenuation values from most to least dense, the stone types were as follows: brushite, weddellite, whewellite, struvite, cystine, and
Fig. 1-Photograph shows stones that were placed in jelly phantom.

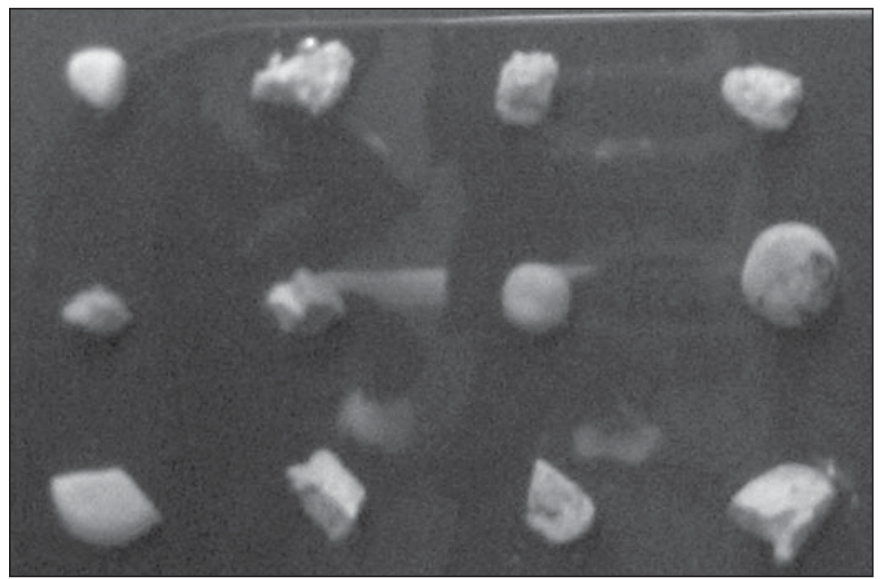




\section{Grosjean et al.}

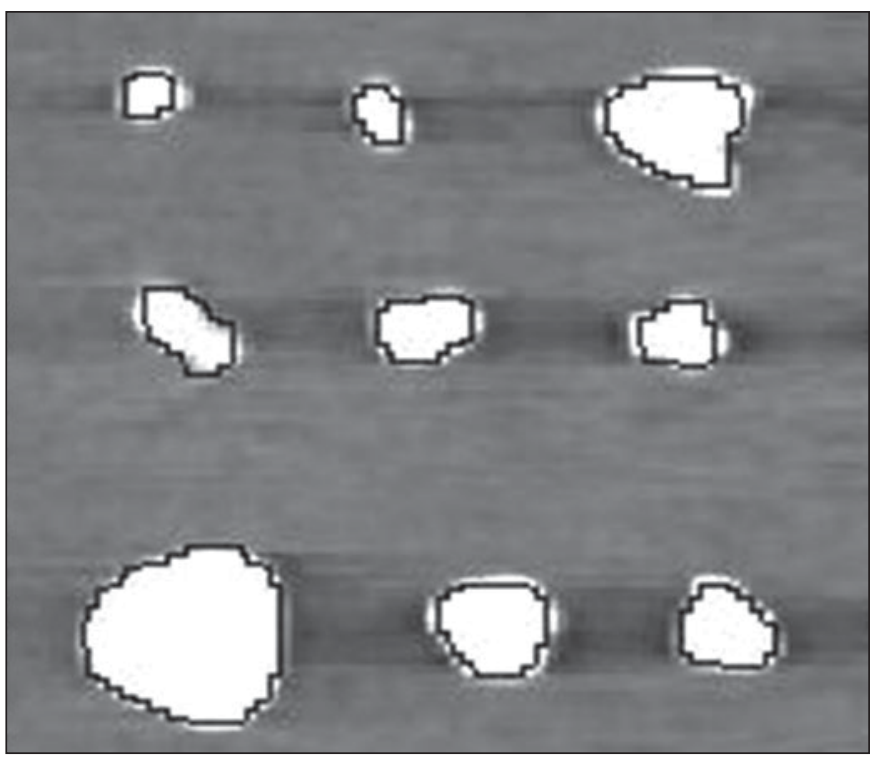

Fig. 2-Diagram shows regions of interest placed within largest area of stones $(120 \mathrm{kV}$; $200 \mathrm{mAs}$; soft-tissue window width, $350 \mathrm{H}$; soft-tissue window length, $40 \mathrm{H}$ ).

TABLE 2: Mean and $95 \%$ Confidence Limits of CT Attenuation Values (H) at Rest of Six Types of Calculi

\begin{tabular}{|c|c|c|c|c|c|c|c|}
\hline \multirow[b]{2}{*}{ Stone Type } & \multirow[b]{2}{*}{$n$} & \multicolumn{3}{|c|}{ Attenuation at $80 \mathrm{kV}$} & \multicolumn{3}{|c|}{ Attenuation at $120 \mathrm{kV}$} \\
\hline & & Lowest & Mean & Highest & Lowest & Mean & Highest \\
\hline $\begin{array}{l}\text { Brushite (calcium hydrogen } \\
\text { phosphate dihydrate) }\end{array}$ & 12 & 1,451 & 1,631 & 1,810 & 1,066 & 1,216 & 1,366 \\
\hline Cystine & 64 & 689 & 731 & 773 & 602 & 625 & 648 \\
\hline $\begin{array}{l}\text { Struvite (magnesium ammonium } \\
\text { phosphate hexahydrate) }\end{array}$ & 29 & 578 & 732 & 865 & 344 & 461 & 578 \\
\hline Uric acid & 38 & 350 & 417 & 484 & 392 & 437 & 482 \\
\hline $\begin{array}{l}\text { Weddellite (calcium oxalate } \\
\text { dihydrate) }\end{array}$ & 35 & 1,235 & 1,341 & 1,547 & 816 & 1,017 & 1,218 \\
\hline $\begin{array}{l}\text { Whewellite (calcium oxalate } \\
\text { monohydrate) }\end{array}$ & 63 & 1,190 & 1,307 & 1,424 & 703 & 797 & 891 \\
\hline
\end{tabular}

uric acid. At $120 \mathrm{kV}$, according to the mean CT attenuation values from most to least dense, the stone types were as follows: brushite, weddellite, whewellite, cystine, struvite, and uric acid. The global sort was identical except for the switch between cystine and struvite. The means and $95 \%$ confidence limits for the CT attenuation values obtained at 80 and $120 \mathrm{kV}$ are reported in Table 2. When the classification of the various types of stones was arranged according to mean CT attenuation value and $95 \% \mathrm{CI}$, substantial overlap between types was found (Fig. 3).

At $80 \mathrm{kV}$, only uric acid stones were identified as a distinct group on the basis of CI. Struvite and cystine stones were not differentiated, but these two groups were differentiated from uric acid, calcium oxalate, and brushite stones. It was difficult to separate whewellite from weddellite and brushite stones (Fig. 3A). At $120 \mathrm{kV}$, cystine stones were clearly identified, but with this energy, uric acid stones were not differentiated from struvite stones. For whewellite, weddellite, and brushite stones, overlap was present but less important than at $80 \mathrm{kV}$ (Fig. 3B).

$\mathrm{CT}$ attenuation values were lower at $120 \mathrm{kV}$ than at $80 \mathrm{kV}$ (Table 2). On average, the CT attenuation values at $120 \mathrm{kV}$ were equal to $75 \%( \pm 17 \mathrm{kV})$ of the value at $80 \mathrm{kV}$. tion values were particularly high for whewellite stones (61\%) and struvite stones (63\%). Despite a larger spread of CT attenuation values at $80 \mathrm{kV}$, there was less overlap at $120 \mathrm{kV}$ (Fig. 3). Only cystine stones at $120 \mathrm{kV}$ and uric acid stones at $80 \mathrm{kV}$ were identified with statistical significance. However, the dual-energy $\mathrm{CT}$ attenuation values obtained nificant differentiation of all types of stones The differences between mean CT attenuaat 80 and at $120 \mathrm{kV}$ allowed statistically sig-
(Fig. 4). Uric acid $(-20 \pm 22 \mathrm{H})$, cystine $(106 \pm 19 \mathrm{H})$, struvite $(271 \pm 16 \mathrm{H})$, weddellite $(323 \pm 5 \mathrm{H})$, brushite $(415 \pm 30 \mathrm{H})$, and whewellite $(510 \pm 17 \mathrm{H})$ were identified as distinct groups.

\section{Difference Between Nonmaintained \\ Breath-Hold and Perfect Breath-Hold}

When motion due to lack of maintenance of a breath-hold was applied to the phantom, the CT attenuation values were significantly different (with 95\% CI) from the CT attenuation values obtained with no motion, except for uric acid at $80 \mathrm{kV}$ (Fig. 5A) and brushite at $120 \mathrm{kV}$ (Fig. 5B). In addition, the CT attenuation values were lower than in the static case except for struvite at $120 \mathrm{kV}$ and whewellite at $120 \mathrm{kV}$. Nevertheless, the classification did not change, and for nonmaintained breath-hold, the classification of stones was similar to the classification obtained with no motion. With nonmaintained breath-hold motion, the overlap was not the same as for the other situations. For example, at $120 \mathrm{kV}$ with no motion, the CI computed for cystine stones $(602-648 \mathrm{H})$ had no overlap with that for the other types of stones. However, when nonmaintained breath-hold motion was applied, the CI of cystine stones $(448-526 \mathrm{H})$ had considerable overlap with that of struvite stones obtained with no motion (344-579 H) (Fig. $5 B)$. Even the dual-energy CT attenuation values did not allow distinction of struvite from uric acid stones or of struvite from weddellite stones (Fig. 6). Only brushite and whewellite were differentiated from the other stones with the dual-energy CT attenuation values.

\section{Difference Between Free-Breathing Motion and Perfect Breath-Hold}

With sinusoidal motion applied to the phantom, the mean CT attenuation values were significantly different (with 95\% CI) from the mean CT attenuation values obtained with no motion, except for struvite at $120 \mathrm{kV}$ (Fig. 5B) and uric acid at $80 \mathrm{kV}$ (Fig. 5A). CT attenuation values were always lower than without motion. The classification of stones was similar to that at rest. Overlap was not the same as that at rest. For example, at $80 \mathrm{kV}$ with no motion, the CI for whewellite stones (1,190$1,424 \mathrm{H})$ had no overlap with that of struvite stones (599-865 H). When free-breathing motion was simulated, the CI for whewellite $(763-1,100 \mathrm{H})$ had considerable overlap with that of struvite stones obtained with no motion (599-865 H) (Fig. 5A). With free-breathing motion, the dual-energy $\mathrm{CT}$ attenuation 


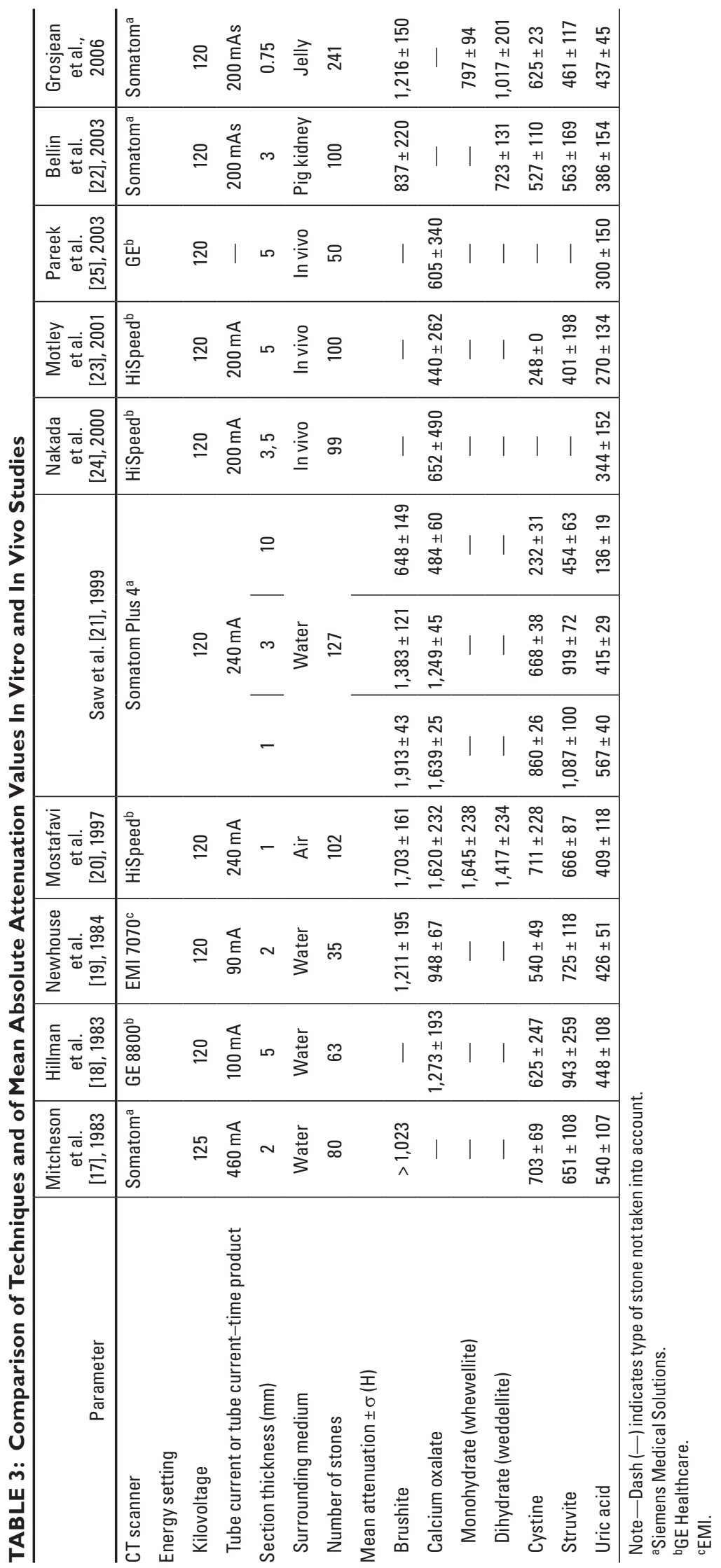

values allowed differentiation of uric acid, struvite, and cystine stones. Brushite, whewellite, and weddellite were not differentiated from one another (Fig. 7).

Difference Between Simulated Free-Breathing Motion and Nonmaintained Breath-Hold

Except for whewellite at $120 \mathrm{kV}$, when nonmaintained breath-hold was simulated $(5 \mathrm{~mm} / \mathrm{s})$, the CT attenuation values were significantly equal (with $95 \% \mathrm{CI}$ ) to the CT attenuation values obtained when freebreathing motion was simulated (Fig. 5B).

\section{Discussion}

Since the early 1980s, several studies have been conducted in an attempt to determine the chemical composition of stones on the basis of X-ray attenuation in vitro and in vivo. For our study, we used the largest number $(n=241)$ of stones so far described, to our knowledge, and found that chemical characterization is possible with dual-energy $\mathrm{CT}$ attenuation values.

In 1998, Mostafavi et al. [20] asserted, having studied only 102 stones, that the best CT parameter for accurately determining the chemical composition of stones was the mean CT attenuation value obtained at $120 \mathrm{kV}$. This affirmation was in accord with our results. At $120 \mathrm{kV}$ the overlap between types of stones was less, and it was easier to differentiate the stone groups. Despite the overlap problem, it was possible to classify the types of stones according to mean CT attenuation value and $95 \% \mathrm{CI}$. At $120 \mathrm{kV}$, from least to most dense, the stones types were as follows: uric acid $(437 \pm 45 \mathrm{H})$, struvite $(461 \pm 117 \mathrm{H})$, cystine $(625 \pm 23 \mathrm{H})$, whewellite $(797 \pm 94 \mathrm{H})$, weddellite $(1,017 \pm 201 \mathrm{H})$, and brushite $(1,216 \pm 150 \mathrm{H})$. In most of the previous studies, the chemical composition of the stones had been assessed only at $120 \mathrm{kV}$. This kilovoltage is the one most commonly used for clinical abdominal imaging. Consequently, only our results obtained at $120 \mathrm{kV}$ can be compared with those of others. Our classification is similar to those of Mitcheson et al. [17], Bachmann et al. [34], and Mostafavi et al. [20]. Hillman et al. [18], Newhouse et al. [19], Saw et al. [21], Bellin et al. [22], and Motley et al. [23] switched cystine and struvite (Table 3). This difference can be explained by the fact that there is often a large overlap between the CI of struvite and the CI of cystine in these studies. Deveci et al. [35] switched whewellite and weddellite, but they used only one weddellite stone, opening the finding to statistical criticism. 


\section{Grosjean et al.}
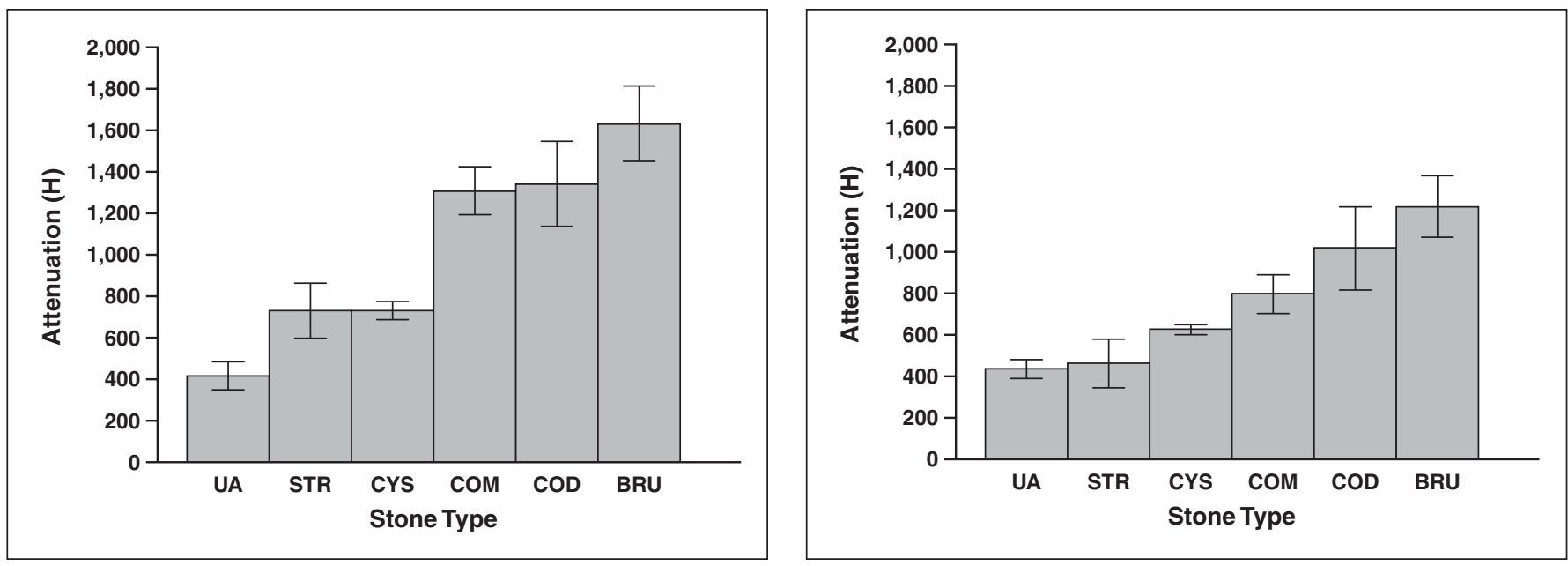

Fig. 3-Graphs show overlap of $95 \% \mathrm{Cls}$ ( $200 \mathrm{mAs}$; gantry rotation time, 0.5 second; collimation, 0.75 at $80 \mathrm{kV}$ [A] and $120 \mathrm{kV}$ [B]). UA = uric acid, STR = struvite, $\mathrm{CYS}=$ cystine, $\mathrm{COM}=$ calcium oxalate monohydrate (whewellite), $\mathrm{COD}=$ calcium oxalate dihydrate (weddellite), $\mathrm{BRU}=$ brushite.

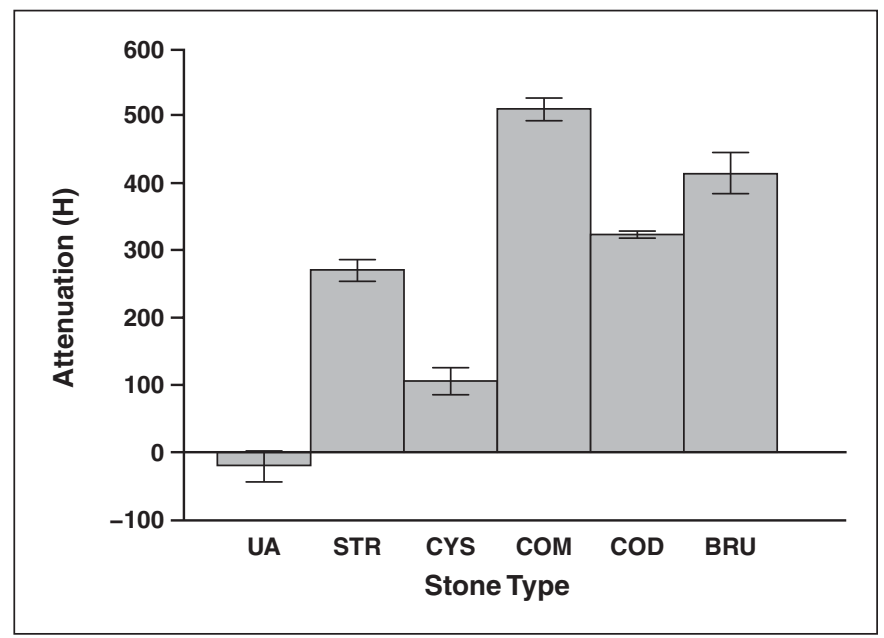

Fig. 4-Graph shows dual-kilovoltage CT attenuation values (attenuation at $80 \mathrm{kV}$ minus attenuation at $120 \mathrm{kV}$ ) obtained with no motion. UA = uric acid, STR = struvite, CYS = cystine, $\mathrm{COM}=$ calcium oxalate monohydrate (whewellite),

COD = calcium oxalate dihydrate (weddellite), $\mathrm{BRU}=$ brushite

$\mathrm{CT}$ attenuation values were $75 \%$ higher at $80 \mathrm{kV}$ than at $120 \mathrm{kV}$, and the classification obtained at $80 \mathrm{kV}$ was not the same as that at $120 \mathrm{kV}$, cystine and struvite being switched. This variation in CT attenuation value determination according to kilovoltage has been described by McKetty [36] and Bushberg [37]. Without motion, for all stones, findings on single-energy scanning ( 80 or $120 \mathrm{kV}$ ) did not allow accurate differentiation of the chemical composition of stones. Dual-energy scanning, however, provided additional information on chemical characterization. As shown by Mostafavi et al. [20], dual-energy CT attenuation values are extremely reliable in differentiating all stones. Even if Mostafavi et al. had been the only investigators to study the six most frequent types of stones (Table 3), they conducted their study without consider- ing renal X-ray attenuation, and the number of stones used could not guarantee the statistical significance of the results.

In our study, the use of the dual-energy CT attenuation values made it possible to characterize all renal stones with statistical significance. In clinical use, imaging for nephrolithiasis is generally performed at $120 \mathrm{kV}$. Because the received dose is proportional to the square of the kilovoltage, use of this technique can lead to an approximately $40 \%$ increase in received dose, possibly less. The second acquisition thus can be minimal (centered on the stone without acquisition of images of the rest of the abdomen) and performed with low energy $(80 \mathrm{kV})$ [38-40]. This additional dose can be a problem for children but can be justified for adult patients because accurate and fast determination of the chemical characterization of renal stones can lead to quicker and more accurate treatment. This new protocol can be facilitated with the dualsource CT (Somatom Definition, Siemens AG Medical Solutions).

Several studies have been conducted in the attempt to determine the chemical composition of renal stones on the basis of in vitro and in vivo X-ray attenuation of the stones (Table 3 ). The in vitro studies, however, did not reproduce normal abdominal wall and fat, perinephric fat, or the spine, causing uncertainty about standardization of the values obtained. For example, Bellin et al. [22] used excised pig kidney placed in water, Mostafavi et al. [20] and Deveci et al. [35] placed stones in air, and Saw et al. [21] placed stones in water. The influence of the surrounding media on CT attenuation values has been proved by Grosjean et al. [41], who found the mean $\mathrm{CT}$ attenuation values of stones vary with the surrounding media tested (air, water, and jelly). This finding can be explained by the beam-hardening effect and insufficient correction of the effect with CT algorithms [42]. In our study, we used a jelly made of water, iodine, and animal proteins and surrounded it with water. The $\mathrm{CT}$ attenuation value of the jelly $(30 \pm 6 \mathrm{H}$ at $120 \mathrm{kV})$ allowed us to reproduce renal attenuation as accurately as possible, but the phantom did not reproduce exactly normal abdominal wall and fat.

The influence of the surrounding media on mean CT attenuation value explains the difference between our values and those obtained in the other studies [20,21,35], which did not respect the normal absorption of the abdomen because the stones were scanned within an 

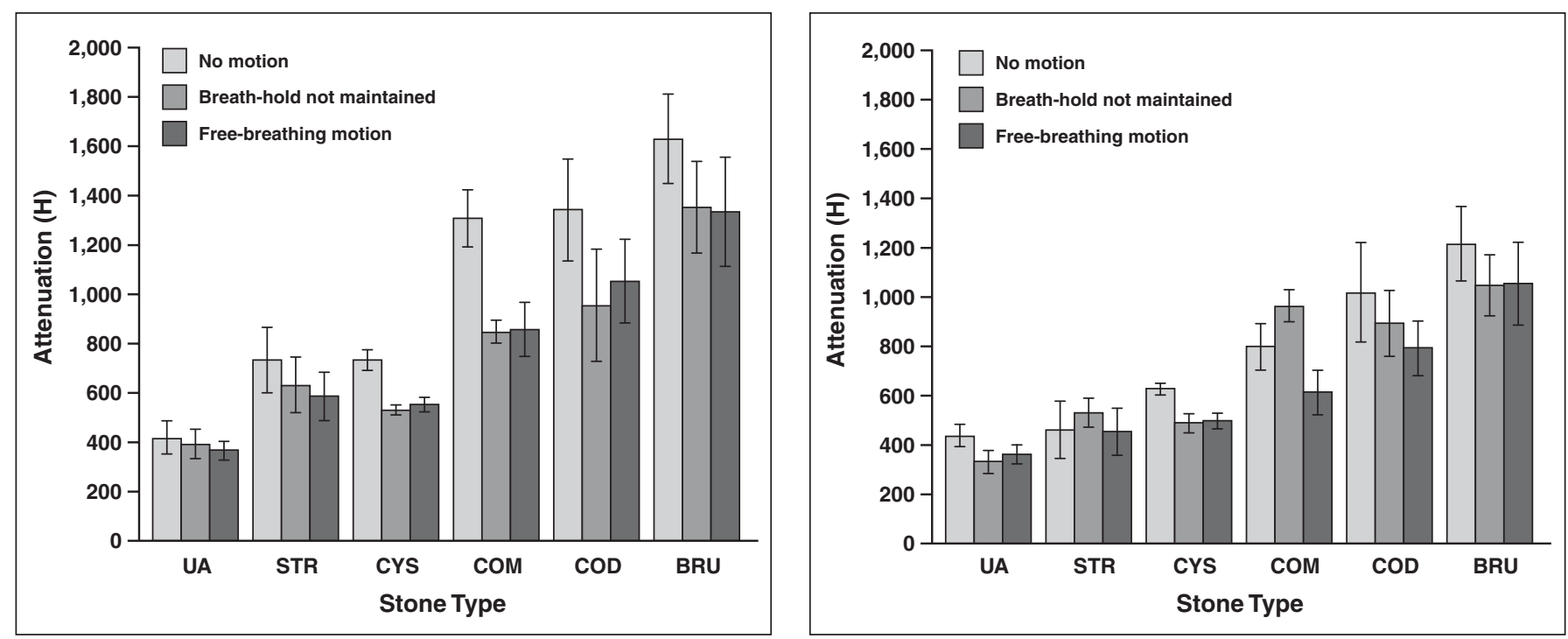

Fig. 5-Graphs show influence of motion on CT attenuation values (attenuation at $80 \mathrm{kV}$ minus attenuation at $120 \mathrm{kV}$ ). UA $=$ uric acid, $\mathrm{STR}=\mathrm{struvite,} \mathrm{CYS} \mathrm{=} \mathrm{cystine,}$ $\mathrm{COM}=$ calcium oxalate monohydrate (whewellite), $\mathrm{COD}=$ calcium oxalate dihydrate (weddellite), $\mathrm{BRU}=$ brushite.

A, Acquisition at $80 \mathrm{kV}$.

B, Acquisition at $120 \mathrm{kV}$.

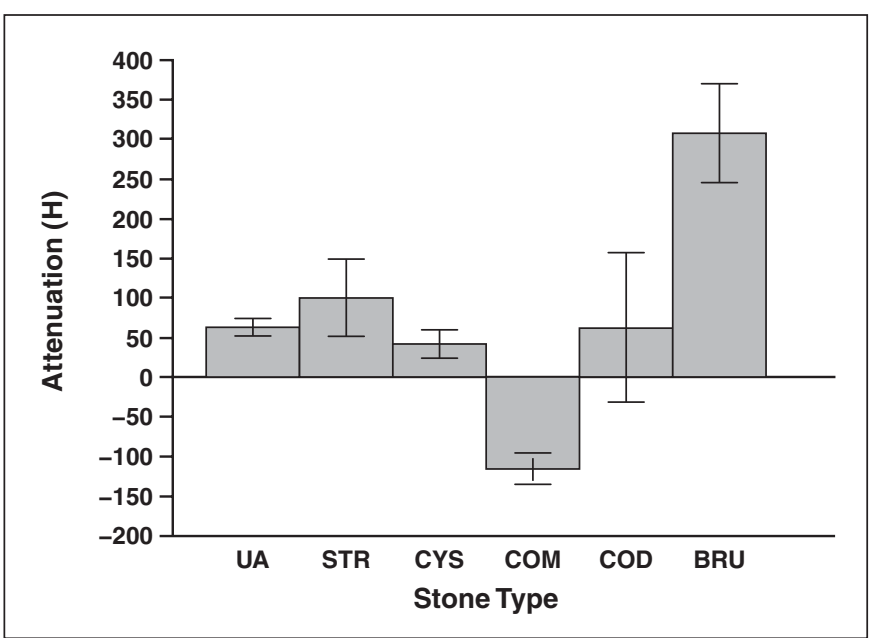

air-filled environment or in water. For example, to prevent overlapping densities and to avoid the absorption of X-ray beams by water or fat, Deveci et al. [35] used an air-filled environment instead of phantoms containing water or fat. Thus the density differences increased, and overlap did not occur. Consequently, because the in vitro conditions were too far from the in vivo conditions, the results cannot be considered a reference for in vivo determination of chemical composition.

Because our study had, to our knowledge, the largest number of stones described in the literature to date, the results have statistical significance for the six most frequent types of stones. Only stones containing at least $85 \%$ of
Fig. 6-Graph shows dual-kilovoltage CT attenuation (attenuation at $80 \mathrm{kV}$ minus attenuation at $120 \mathrm{kV}$ ) obtained with simulated lack of maintenance of breath-hold. UA = uric acid, STR = struvite, CYS = cystine, $\mathrm{COM}=$ calcium oxalate monohydrate (whewellite), $\mathrm{COD}=$ calcium oxalate dihydrate (weddellite) $\mathrm{BRU}=$ brushite . one component and having low content of a secondary component were used. These stones can legitimately be considered to reflect the behavior of the principal component and in consequence can be considered pure. Overrepresentation of some components (for example, calcium oxalate monohydrate and brushite) was deliberate because of their particular resistance to extracorporeal shock wave lithotripsy. Carbapatite stones were not included in our study because they are rarely pure and almost always are multiphasic with high content of a secondary component. It was also difficult to collect enough pure carbapatite stones to obtain significant results. Pure carbapatite stones are, in practice, less frequent than cystine stones. Our stones were selected from the purest possible stones. Even though most stones are polycrystalline, it was necessary to work with pure stones or stones considered pure. Because differentiation of pure stones has not been proved, study of mixed stones would not be realistic.

Our phantom was closer to in vivo conditions than phantoms used in in vitro studies of the X-ray attenuation of the kidney. With this phantom and the large number of stones, we attempted to prove that dual-energy CT attenuation values can be clinically useful for determining the chemical composition of pure renal stones. However, even if a breathhold can generally be maintained over the acquisition time, for some patients (e.g., those with sharp pain due to renal colic, children, and dyspneic patients), a breath-hold is particularly difficult [43]. To analyze the influence of motion on the X-ray attenuation of stones, two types of motion were applied to the phantom: free-breathing motion and motion due to lack of maintenance of a breathhold. We found that CT attenuation values depend on motion. With the two types of movement, CT attenuation values generally decreased. With either type of motion, the mean CT attenuation values were significantly different from those obtained at rest. Therefore, even dual-energy CT attenuation values cannot be used to determine the chemical composition of renal stones in the presence of motion. 


\section{Grosjean et al.}

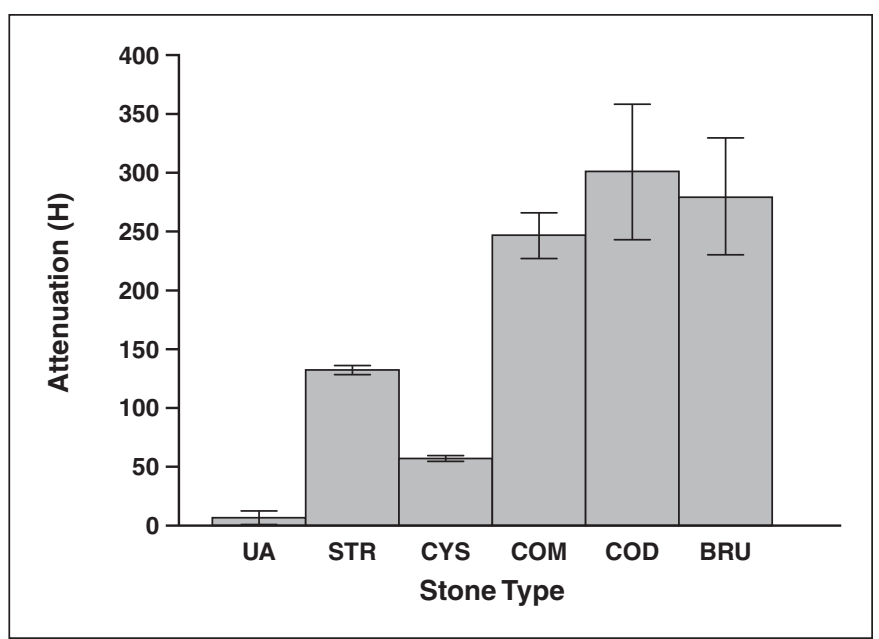

Fig. 7-Graph shows dual-kilovoltage CT attenuation values (attenuation at $80 \mathrm{kV}$ minus attenuation at $120 \mathrm{kV}$ ) obtained with simulated free-breathing motion. UA = uric acid, STR = struvite, CYS $=$ cystine, $\mathrm{COM}=$ calcium oxalate monohydrate (whewellite) $\mathrm{COD}=$ calcium oxalate dihydrate (weddellite), $\mathrm{BRU}=$ brushite

The explanation for the influence of motion is the partial volume effect due to motion. With $16 \times 0.75 \mathrm{~mm}$ collimation and a gantry rotation time of 0.5 second, $24 \mathrm{~mm}$ are scanned per second, but in that time, the stones have moved at least $5 \mathrm{~mm}$ with lack of maintenance of a breath-hold. The partial volume effect occurs during imaging of any part of the body in which the anatomic relations are changing rapidly in the $z$ direction [44]. To keep the partial volume effect at a minimum, the thinnest available slice thickness has to be used. In addition, acquisition time generally increases when slice thickness is decreased. The longer the acquisition time, the greater is the partial volume effect due to the presence of motion. Because of this partial volume effect paradox, a compromise between slice thickness and acquisition time is needed. To minimize the acquisition time, gantry rotation time can be decreased. It is noteworthy that the gantry rotation time of 500 milliseconds did not allow minimization of motion artifacts but corresponds to the abdominal imaging protocol in current clinical use. Even with the fastest available gantry rotation time (420 milliseconds), it is impossible to remove motion artifacts. Ritchie et al. [29] found that the gantry rotation time necessary to eliminate motion artifacts caused by quiet breathing was 93.5 milliseconds.

Our results indicate that determination of the chemical composition of renal stones has to be done with images obtained during a perfect breath-hold. We can never be sure, however, that a patient has realized a perfect breath-hold. Imprecision due to motion is a limitation of CT determination of the chemical composition of renal stones. Without motion, prediction of renal stone composition with dual-energy CT attenuation values is reliable. When motion is applied, the technique becomes unusable.

Saw et al. [21] scanned 127 urinary stones of known composition placed in a water bath $(120 \mathrm{kV}, 240 \mathrm{~mA})$. By referring to the model of Hu and Fox [45], which showed that measurement of the CT attenuation value of an object with helical CT is affected by collimation width and pitch, Saw et al. found that the measured attenuation of stones declined with increasing collimation width owing to the partial volume effect. In addition, scanning 63 stones in a waterbath $(120 \mathrm{kV}, 100 \mathrm{~mA})$, Hillman et al. [18] found that even if it is clear that small stones will be subject to partial volume inaccuracies in measurement of CT attenuation and that this source of inaccuracy can be further accentuated by the respiratory movement of a patient, CT may prove a valuable adjunct to traditional laboratory and clinical methods of establishing the chemical composition of stones. To avoid partial volume inaccuracies, we chose the thinnest possible slice thickness for our study $(0.75 \mathrm{~mm})$. It is essential to use a narrow slice width to ensure the accuracy of attenuation values in helical CT [46]. But decreasing the slice thickness has two opposing effects. Stone detection can be improved with a decrease in partial volume effect, but it can hampered by an increase in noise [47-49]. In addition, choosing table feed values greater than the nominal section thicktivity profile [50]. For lesions smaller than the section thickness, a reduction in contrast enhancement due to the partial volume effect can be observed.

There may be variability in CT attenuation values of scans obtained with different $\mathrm{CT}$ ness increases degradation of the slice sensi- scanners manufactured by different companies and even among different scanners made by the same manufacturer and of the same model $[51,52]$. This phenomenon may explain the slight variations in CT reports of attenuation values. In addition, most renal stones in humans are not pure. Heterogeneity can be very important, and the proportion of constituents can vary considerably $[46,53,54]$. To determine absolute CT attenuation values, Mostafavi et al. [20] used 1-pixel ROIs to measure CT attenuation. Deveci et al. [35] used three $0.01-\mathrm{cm}^{2}$ ROIs. In applying these methods, the investigators did not take into account the structural heterogeneity of mixed calculi. Because of this structural heterogeneity, we used the largest ROI within a stone to obtain a reliable mean $\mathrm{CT}$ attenuation value for each stone, as did Motley et al. [23]. When motion is applied, however, the larger the ROI, the more pixels from the environment of the stone can be included and lead to an increase in partial volume effect.

A limitation of our study was that only stones with a diameter between 7 and $25 \mathrm{~mm}$ were assessed. The influence of stone size on CT attenuation values was not studied. The results can be degraded when the diameter of the stones approaches the slice thickness. The effect of stone size will be the subject of future work.

In conclusion, with single-energy CT, overlap between types of renal stones makes it difficult to reliably determine the chemical composition. Dual-energy CT attenuation values can be used for accurate prediction of stone composition in vitro. When slight motion is applied to renal stones during acquisition, however, CT attenuation values and even dual-energy CT attenuation values became significantly different from those obtained at rest and consequently can lead to confusion between stone types. Therefore, for in vivo application of this technique, a perfect breath-hold has to be performed by the patient, even during MDCT.

\section{References}

1. Levine JA, Neitlich J, Verga M, Dalrymple N, Smith RC. Ureteral calculi in patients with flank pain: correlation of plain radiography with unenhanced helical CT. Radiology 1997; 204:27-31

2. Sommer FG, Jeffrey RB Jr, Rubin GD, et al. Detection of ureteral calculi in patients with suspected renal colic: value of reformatted noncontrast helical CT. AJR 1995; 165:509-513

3. Olcott EW, Sommer FG, Napel S. Accuracy of detection and measurement of renal calculi: in 


\section{MDCT of Renal Stones}

vitro comparison of three-dimensional spiral CT, radiography, and nephrotomography. Radiology 1997; 204:19-25

4. Smith RC, Rosenfield AT, Choe KA, et al. Acute flank pain: comparison of non-contrast-enhanced CT and intravenous urography. Radiology 1995 194:789-794

5. Fielding JR, Steele G, Fox LA, Heller H, Loughlin KR. Spiral computerized tomography in the evaluation of acute flank pain: a replacement for excretory urography. J Urol 1997; 157:2071-2073

6. Yilmaz S, Sindel T, Arslan G, et al. Renal colic: comparison of spiral CT, US and IVU in the detection of ureteral calculi. Eur Radiol 1998; 8:212-217

7. Dalla Palma L, Pozzi-Mucelli R, Stacul F. Present-day imaging of patients with renal colic. Eur Radiol 2001; 11:4-17

8. Hubert J, Blum A, Cormier L, Claudon M, Regent D, Mangin P. Three-dimensional CT-scan reconstruction of renal calculi: a new tool for mapping out staghorn calculi and follow-up of radiolucent stones. Eur Urol 1997; 31:297-301

9. Katz DS, Lane MJ, Sommer FG. Non-contrast spiral CT for patients with suspected renal colic. Eur Radiol 1997; 7:680-685

10. Preminger GM, Vieweg J, Leder RA, Nelson RC. Urolithiasis: detection and management with unenhanced spiral CT-a urologic perspective. Radiology 1998; 207:308-309

11. Wang LJ, Wong YC, Chuang CK, et al. Predictions of outcomes of renal stones after extracorporeal shock wave lithotripsy from stone characteristics determined by unenhanced helical computed tomography: a multivariate analysis. Eur Radiol 2005; 15:2238-2243

12. Dretler SP, Spencer BA. CT and stone fragility. J Endourol 2001; 15:31-36

13. Zhong P, Preminger GM. Mechanisms of differing stone fragility in extracorporeal shockwave lithotripsy. J Endourol 1994; 8:263-268

14. Renner C, Rassweiler J. Treatment of renal stones by extracorporeal shock wave lithotripsy. Nephron 1999; 81[suppl 1]:71-81

15. Rassweiler JJ, Renner C, Chaussy C, Thuroff S. Treatment of renal stones by extracorporeal shockwave lithotripsy: an update. Eur Urol 2001; 39:187-199

16. Williams JC Jr, Saw KC, Paterson RF, Hatt EK, McAteer JA, Lingeman JE. Variability of renal stone fragility in shock wave lithotripsy. Urology 2003; 61: 1092-1096

17. Mitcheson HD, Zamenhof RG, Bankoff MS, Prien EL. Determination of the chemical composition of urinary calculi by computerized tomography. $J$ Urol 1983; 130:814-819

18. Hillman BJ, Drach GW, Tracey P, Gaines JA. Computed tomographic analysis of renal calculi.
AJR 1984; 142:549-552

19. Newhouse JH, Prien EL, Amis ES Jr, Dretler SP, Pfister RC. Computed tomographic analysis of urinary calculi. AJR 1984; 142:545-548

20. Mostafavi MR, Ernst RD, Saltzman B. Accurate determination of chemical composition of urinary calculi by spiral computerized tomography. J Urol 1998; 159:673-675

21. Saw KC, McAteer JA, Monga AG, Chua GT, Lingeman JE, Williams JC Jr. Helical CT of urinary calculi: effect of stone composition, stone size, and scan collimation. AJR 2000; 175:329-332

22. Bellin MF, Renard-Penna R, Conort P, et al. Helical CT evaluation of the chemical composition of urinary tract calculi with a discriminant analysis of CT attenuation values and density. Eur Radio 2004; 14:2134-2140

23. Motley G, Dalrymple N, Keesling C, Fischer J, Harmon W. Hounsfield unit density in the determination of urinary stone composition. Urology 2001; 58:170-173

24. Nakada SY, Hoff DG, Attai S, Heisey D, Blankenbaker D, Pozniak M. Determination of stone composition by noncontrast spiral computed tomography in the clinical setting. Urology 2000 55:816-819

25. Pareek G, Armenakas NA, Fracchia JA. Hounsfield units on computerized tomography predict stone-free rates after extracorporeal shock wave lithotripsy. J Urol 2003; 169:1679-1681

26. Brandner ED, Wu A, Chen H, et al. Abdominal organ motion measured using 4D CT. Int J Radiat Oncol Biol Phys 2006; 65:554-560

27. McCollough CH, Bruesewitz MR, Daly TR, Zink FE. Motion artifacts in subsecond conventional CT and electron-beam CT: pictorial demonstration of temporal resolution. RadioGraphics 2000 20:1675-1681

28. Alfidi RJ, MacIntyre WJ, Haaga JR. The effects of biological motion on CT resolution. AJR 1976; 127:11-15

29. Ritchie CJ, Godwin JD, Crawford CR, Stanford W, Anno H, Kim Y. Minimum scan speeds for suppression of motion artifacts in CT. Radiology 1992; 185:37-42

30. Grosjean R, Guerra RM, Lorentz C, et al. Dynamic platform for moving organ moving. Progress in biomedical optics and imaging 2006: proceedings of SPIE medical imaging 2006-physics of medical imaging, vol. 6142. Bellingham, WA: SPIE, 2006:1137-1147

31. Lujan AE, Ten Haken RK, Larsen EW, Balter JM. Quantization of setup uncertainties in 3-D dose calculations. Med Phys 1999; 26:2397-2402

32. Moerland MA, van den Bergh AC, Bhagwandien $\mathrm{R}$, et al. The influence of respiration induced motion of the kidneys on the accuracy of radiotherapy treatment planning, a magnetic resonance im- aging study. Radiother Oncol 1994; 30:150-154

33. Pasquier C, Odille F, Abaecherli R, Vuissoz PA, Felblinger J. Modeling of organ's motion using external sensors. Proceedings of the ISMRM 14th scientific meeting and exhibition. Berkeley, CA: International Society for Magnetic Resonance in Medicine, 2006

34. Bachmann R, Heimbach D, Kersjes W, Jacobs D, Schild $\mathrm{H}$, Hesse A. A new type of artificial urinary calculi: in vitro study by spiral CT. Invest Radiol 2000; 35:672-675

35. Deveci S, Coskun M, Tekin MI, Peskircioglu L, Tarhan NC, Ozkardes H. Spiral computed tomography: role in determination of chemical compositions of pure and mixed urinary stones - an in vitro study. Urology 2004; 64:237-240

36. McKetty MH. The AAPM/RSNA physics tutorial for residents: X-ray attenuation. RadioGraphics 1998; 18:151-163

37. Bushberg JT. The AAPM/RSNA physics tutorial for residents: X-ray interactions. RadioGraphics 1998; 18:457-468

38. Liu W, Esler SJ, Kenny BJ, Goh RH, Rainbow AJ, Stevenson GW. Low-dose nonenhanced helical CT of renal colic: assessment of ureteric stone detection and measurement of effective dose equivalent. Radiology 2000; 215:51-54

39. Spielmann AL, Heneghan JP, Lee LJ, Yoshizumi $\mathrm{T}$, Nelson RC. Decreasing the radiation dose for renal stone CT: a feasibility study of single- and multidetector CT. AJR 2002; 178:1058-1062

40. Kalra MK, Maher MM, Toth TL, et al. Strategies for CT radiation dose optimization. Radiology 2004; 230:619-628

41. Grosjean R, Kermarrec I, Sauer B, et al. Determination of the chemical composition of human renal stones with MDCT: influence of the surrounding media. Progress in biomedical optics and imaging: proceedings of SPIE medical imaging 2007-physiology, function, and structure from medical images, vol. 6511. Bellingham, WA: SPIE, 2007:1228-1236

42. Maki DD, Birnbaum BA, Chakraborty DP, Jacobs JE, Carvalho BM, Herman GT. Renal cyst pseudoenhancement: beam-hardening effects on CT numbers. Radiology 1999; 213:468-472

43. Remy-Jardin M, Tillie-Leblond I, Szapiro D, et al. CT angiography of pulmonary embolism in patients with underlying respiratory disease: impact of multislice CT on image quality and negative predictive value. Eur Radiol 2002; 12:1971-1978

44. Barrett JF, Keat N. Artifacts in CT: recognition and avoidance. RadioGraphics 2004; 24:1679-1691

45. Hu H, Fox SH. The effect of helical pitch and beam collimation on the lesion contrast and slice profile in helical CT imaging. Med Phys 1996; 23:1943-1954

46. Zarse CA, McAteer JA, Tann M, et al. Helical 


\section{Grosjean et al.}

computed tomography accurately reports urinary stone composition using attenuation values: in vitro verification using high-resolution microcomputed tomography calibrated to Fourier transform infrared microspectroscopy. Urology 2004; 63:828-833

47. Scheck RJ, Coppenrath EM, Kellner MW, et al. Radiation dose and image quality in spiral computed tomography: multicentre evaluation at six institutions. Br J Radiol 1998; 71:734-744

48. Shin HO, Falck CV, Galanski M. Low-contrast detectability in volume rendering: a phantom 16:161-165 study on multidetector-row spiral CT data. Eur Radiol 2004; 14:341-349

49. Ketelslegers E, Van Beers BE. Urinary calculi: improved detection and characterization with thin-slice multidetector CT. Eur Radiol 2006;

50. Polacin A, Kalender WA, Marchal G. Evaluation of section sensitivity profiles and image noise in spiral CT. Radiology 1992; 185:29-35

51. Groell R, Rienmueller R, Schaffler GJ, Portugaller HR, Graif E, Willfurth P. CT number variations due to different image acquisition and reconstruc- tion parameters: a thorax phantom study. Comput Med Imaging Graph 2000; 24:53-58

52. Levi, C, Gray JE, McCullough EC, Hattery RR. The unreliability of CT numbers as absolute values. AJR 1982; 139:443-447

53. Daudon M, Donsimoni R, Hennequin C, et al. Sex- and age-related composition of $10617 \mathrm{cal}$ culi analyzed by infrared spectroscopy. Urol Res $1995 ; 23: 319-326$

54. Daudon M, Lacour B, Jungers P. Influence of body size on urinary stone composition in men and women. Urol Res 2006; 34:193-199 